\title{
Learning Medicine
}

\section{Starting medicine: the basic medical sciences course}

\author{
PETER RICHARDS
}

The first few weeks at medical school are bewildering. The first two years are filled with facts, sometimes heavy going, and in many schools a little tantalising for those who are understandably impatient to get to grips with patients and disease. Although there is much to learn there is no excuse for it being dull.

Anatomy, the structure of the human body (including embryology, its process of development); physiology, the normal function; biochemistry, the chemistry of body processes; pharmacology, the properties and metabolism of drugs in the body; psychology and sociology, the basis of human behaviour; and general pathology, the general principles of the mechanisms of disease, form the core of the first two years' work. The extent to which this instruction is integrated with and taught through glimpses of patients and their disease differs among schools.

\section{The subjects taught}

Anatomy is taught partly by dissection of dead bodies (cadavers), partly by the use of microscope slides, and partly as a living subject with models or patients. It is no longer necessary for students to own a microscope. At many schools students dissect the whole body in groups over one year, working on one part at a time: arm, chest, head and neck, leg, and abdomen. The dissecting room is an unpleasant shock at first but not for long.

Tutorials and closed circuit television demonstrations in the dissecting room are used to guide dissection and progress is checked and consolidated by frequent oral examinations. Surface anatomy in living people and radiological anatomy are components of all courses. Dissection may seem to waste time when only one or two in each group of students can be dissecting at once, but it is a well tried method of learning; some schools now teach all except the most important areas by demonstration of prosected specimens and not by dissection. Preserved cadavers make for difficult dissection; fortunately much of the knowledge of anatomy necessary for clinical practice is revised and extended later by helping at surgical operations.

Other subjects are taught by lectures, laboratory practicals, demonstrations, films, tutorials, and projects. Often students perform simple tests on themselves under supervision in physiology and pharmacology practicals; it is a good way both to learn and to begin to appreciate what patients endure. Projects help to develop the ability to think, to reason and to escape from the forced feeding of fact which forms too large a part of traditional medical courses and tends to stifle curiosity. Project work also makes it necessary to discover how to make full use of the library. The only substantial opportunity for supervised

St Mary's Hospital Medical School, London W2 1PG PETER RICHARDS, MD, FRCP, dean and professor of medicine laboratory research in the preclinical years comes from honours courses that are either an integral part of the course or intercalated (see below).

Preclinical courses are gradually becoming more coordinated and more specifically directed towards the vocational aspects of medicine. Each subject has a central core of knowledge special to itself but once that has been outlined there is much to be said for teaching structure and function simultaneously, building up knowledge body system by body system. For example, it is logical to teach together the anatomy and physiology of the heart and circulatory system. Normal function is often best understood by its breakdown in disease, as, for example, in inherited metabolic diseases, and here the clinician can make a valuable contribution to the preclinical teaching by discussing and demonstrating patients as examples.

\section{Tutors, teachers, and assessments}

Tutorial teaching in small groups supplements larger group teaching and gives a better opportunity to question and discuss. Many schools also have a coordinating tutor or vice dean to students on the preclinical course who keeps an eye on their overall academic programme and progress during the first two or three years of the course. Students may also have a personal tutor, a member of staff detailed to be a friend and adviser. The success or failure of the personal tutor system depends on the individuals concerned. On the whole students seem to prefer to obtain personal advice from sympathetic staff members with whom they have day by day contact during the course rather than to seek out a contrived adviser with whom there may be no natural contact. In many schools students also play a part in befriending other students-for example, a second year student may take some responsibility for a first year student, and a clinical student for a preclinical student.

The form of the preclinical course probably matters much less than the quality and enthusiasm of its teachers. No particular curriculum has been proved to be better than others, not least because it is far from clear when and how to measure success. Creating and sustaining interest and stimulating critical thought are in my view the most important goals. Interest is best sustained by showing the clinical relevance of science to medicine; a preclinical student commented that "examples of clinical applications give you enough energy and curiosity to keep going for another couple of weeks."

The balance between continuous assessment during the course and major examinations at the end of the year varies considerably. Students at traditional schools which rely almost completely on an end of year examination usually wish that more credit was given to performance during the course. Students at schools which have largely replaced major examinations by continuous assessment complain instead at the stress and strain of frequent tests throughout the year. It is a matter of individual preference.

Five to ten per cent of medical students fail to complete the course. Most fail at the end of the first year (because of mis- 
judgment of the amount of work necessary, failure to learn to organise their own work, waning of motivation, or because of the diversion of personal entanglements). A few fail at the end of the second year. If examinations held in June of each of the first two years are failed they must be passed at second attempt in September. Students rarely drop out in the clinical years: a change of heart or illness are the usual reasons.

\section{Intercalated honours degrees}

Grants are made available through the Medical Research Council for $10 \%$ to $15 \%$ of students at schools with a two year preclinical course to undertake an intercalated BSc honours degree in a third preclinical year. Their contemporaries go straight on into the clinical course. A wide range of BSc courses is available in different schools and includes single subject courses in a preclinical science department or a combination of course units in different departments, such as "infection and immunity" courses mounted jointly by departments of medical microbiology and immunology. London University students can arrange to undertake an intercalated BSc in a college other than their own medical school.

There are several attractions of taking an intercalated BSc degree which more than outweigh the disadvantage of losing immediate contact with colleagues with whom the first two years have been spent and of lengthening the course by one year. The advantages include the development of a critical approach, a training in laboratory and library research procedures, and education in depth in a field of science often chosen to have direct relevance to the understanding of clinical medicine. It is useful to have a BSc degree to mark the years of study of sciences related to medicine because it provides a qualification which most students do not have when they enter the keen competition for postgraduate training posts. A science degree is also useful to the occasional student who drops out of the medical course and would otherwise have nothing to show for several years of university work. Clinical teachers used to regard an intercalated $\mathrm{BSc}$ as irrelevant to clinical training but this attitude is passing, not least because of the increasing relevance of the subjects of BSc courses to the understanding of disease.

\title{
Aviation Medicine
}

\section{Legal aspects of inflight emergencies}

\author{
P J C CHAPMAN
}

In a series of articles on aviation medicine published recently in the $B M \mathcal{F}$ the authors referred to medical emergencies occurring in passenger aircraft and the part that a doctor who might be on board could be called on to play. ${ }^{1}$ This has awoken a latent interest, in some cases even a nagging fear, in the minds of some practitioners concerning the medicolegal implications of such a dilemma.

What is clearly required is an authoritative guide to spell out the exact implications of every dilemma that could develop. Alas, this is not only impossible in the context of air travel: it is equally impossible in any parallel problem that might occur on the ground. Were it not so there would be no need for lawyers and judges. All that can be sensibly afforded are some general principles that are likely to be relevant to such circumstances.

\section{British registered aircraft}

Because the number of variables in international travel is almost infinite it is best to consider the most straightforward problem and assume that a British owned and registered aircraft is flying within the United Kingdom in which a British subject resident within the country becomes ill and is treated by a doctor who is a fellow passenger. What then are the liabilities, given that the person responding is fully registered to practise medicine here? The answer is straightforward and the responsibility and obligations no different from those occurring daily in doctors' lives. The doctor will be expected to act with the same reasonable professional skill as he would on

British Caledonian Airways Ltd, Crawley, West Sussex

P J C CHAPMAN, MB, DPH, chief medical officer the ground below but within the physical restraints-such as limited space, noise, and basic equipment-that inflight conditions impose. His judgment must always ultimately rest on the patient's best interest, which may not always accord with his and his fellow travellers' convenience. He would have to remember to act only within the ambit of his own professional skills and not-if an alternative exists, as it may-exceed them.

If the doctor comes forward as a result of a call for help from the crew, rather than volunteering his services direct to his fellow passenger, then he will technically be acting on their behalf and thus on behalf of the aircraft operators. This raises another facet to this apparently simple problem and concerns the responsibility of the airline themselves. They cannot be held responsible for the doctor's professional actions but they must, through the cabin staff, take reasonable care themselves to ensure that so far as it lies within their power this volunteer really is a bona fide medical practitioner and not, as has occurred, a deliberate or inadvertent imposter. There is a clear duty of care on them to do what they can to check this point and it is equally clear that such inquiries may well give offence to the doctor concerned. Even if documents, such as a passport, are available and even if these can be asked for and produced without the appearance of overzealous susficion they may be inconclusive. Many who are not medical practitioners may yet use the style of "doctor."

One of the peculiarities of inflight illness is that a basic question to be answered must always be whether the flight can be continued to its destination or whether a premature diversionary landing has to be made. The latter may not be popular with anyone, but it is a decision that may have to be made as early as possible. This has to be related to the fact that the patient's apparent condition may well be one with which a doctor may be entirely unfamiliar after perhaps a lifetime's 